\title{
SUBSURFACE (SSF) CONSTRUCTED WETLAND UNTUK PENGOLAHAN AIR LIMBAH LAUNDRY
}

\author{
Rhenny Ratnawati ${ }^{1)}$ dan Aprilia Talarima ${ }^{1)}$ \\ 1) Program Studi Teknik Lingkungan; Fakultas Teknik Sipil dan Perencanaan \\ Universitas PGRI Adi Buana Surabaya \\ Email: ratnawati@unipasby.ac.id
}

\begin{abstract}
Abstrak
Air limbah laundry mengandung kadar amonium $\left(\mathrm{NH}_{3}\right)$, fosfor $\left(\mathrm{PO}_{4}\right)$, dan deterjen yang tinggi. Constructed wetland atau sistem rawa buatan merupakan salah satu alternatif teknologi yang sederhana, mempunyai biaya operasional dan pemeliharaan yang relatif murah untuk mengolah air limbah laundry. Berbagai jenis tumbuhan dapat tumbuh dalam sistem SSF constructed wetland. Penelitian ini bertujuan: 1) mengkaji kadar $\mathrm{NH}_{3}$ dan $\mathrm{PO}_{4}$ pada limbah laundry dengan SSF constructed wetland, 2) mengkaji kemampuan tumbuhan melati air (Echinodorus palaefolius) dan kayu apu (Pistia stratiotes L.) dalam penurunan kadar $\mathrm{NH}_{3}$ dan $\mathrm{PO}_{4}$. Penelitian dilakukan dalam skala laboratorium dengan sistem kontinyu. Variasi jenis tumbuhan yang digunakan adalah melati air (Echinodorus palaefolius) dan kayu apu (Pistia stratiotes L.). Air limbah laundry diambil dari salah satu usaha industri laundry skala rumah tangga di daerah Sidoarjo. Parameter yang diukur adalah nilai suhu, $\mathrm{pH}$, kadar $\mathrm{NH}_{3}$, dan $\mathrm{PO}_{4}$. Tumbuhan yang akan digunakan pada penelitian memiliki kondisi awal dengan umur dan tinggi yang sama. Hasil penelitian menunjukkan bahwa efisiensi penurunan kadar $\mathrm{NH}_{3}$ adalah sebesar 70-82\%, sedangkan penurunan kadar $\mathrm{PO}_{4}$ mencapai $83-88 \%$. Jenis tumbuhan yang paling efektif dalam menurunkan kadar $\mathrm{NH}_{3}$ dan $\mathrm{PO}_{4}$ pada air limbah laundry dengan menggunakan SSF constructed wetland adalah tumbuhan melati air (Echinodorus palaefolius).
\end{abstract}

Kata kunci: Air limbah laundry, Amonia (NH3), Kayu apu (Pistia stratiotes L.), Melati air (Echinodorus palaefolius), Fosfor ( $\left.\mathrm{PO}_{4}\right)$, Subsurface constructed wetland.

\begin{abstract}
Laundry waste contains high ammonium $\left(\mathrm{NH}_{3}\right)$, phosphor $\left(\mathrm{PO}_{4}\right)$, and detergent. Constructed wetland is considered a simplest alternative technology, low operational and maintenance costs for processing the laundry waste. Different types of plants can grow in a constructed wetland system. The aims of this study are: 1) to investigate $\mathrm{NH}_{3}$ and $\mathrm{PO}_{4}$ levels in laundry waste with SSF constructed wetland, 2) to investigate the ability of Echinodorus palaefolius and Pistia stratiotes L. in decreasing levels of $\mathrm{NH}_{3}$ and $\mathrm{PO}_{4}$. The study was conducted on a laboratory scale with a continuous system. Variations of plant species used are Echinodorus palaefolius and Pistia stratiotes L.. Laundry waste water is taken from one household-scale laundry business in Sidoarjo. The measured parameters were temperature, $\mathrm{pH}, \mathrm{NH}_{3}$, and $\mathrm{PO}_{4}$. Plants to be used in the study have the initial conditions with the same age and height. The results showed that the efficiency of $\mathrm{NH}_{3}$ decreased by 70-82\%, while the decrease of $\mathrm{PO}_{4}$ level reached 83-88\%. The most effective plant species in reducing levels of $\mathrm{NH}_{3}$ and $\mathrm{PO}_{4}$ in laundry wastewater using SSF constructed wetland is Echinodorus palaefolius.
\end{abstract}

Keywords: Ammonia (NH3), Constructed wetland, Echinodorus palaefolius, Laundry waste, Pistia stratiotes L., Phosphor $\left(\mathrm{PO}_{4}\right)$ 


\section{PENDAHULUAN}

Industri laundry merupakan salah satu industri skala rumah tangga yang saat ini sedang berkembang dengan pesat. Pertumbuhan jasa laundry yang semakin naik ini tidak diiringi dengan pengolahan air limbah laundry yang baik. Air limbah laundry biasanya langsung dibuang begitu saja ke badan air penerima tanpa adanya pengolahan terlebih dahulu. Air sisa proses kegiatan mencuci sendiri mengandung kadar amonium $\left(\mathrm{NH}_{3}\right)$, fosfat $\left(\mathrm{PO}_{4}\right)$, dan deterjen yang tinggi (Hardyanti dan Rahayu, 2007). Selain itu, terdapat pula berbagai macam organisme pada air limbah laundry, seperti bakteri, jamur, dan organisme air sejenisnya (Sperling, 2007). Kandungan nutrien (N dan P) yang tinggi pada air limbah laundry inilah yang menyebabkan terjadinya eutrofikasi pada badan air penerima (Stefhany dkk., 2013). Oleh karena itu, diperlukan alternatif teknologi pengolahan air limbah laundry yang mampu mengatasi permasalahan tersebut.

Constructed wetland atau sistem rawa buatan merupakan salah satu alternatif teknologi yang sederhana, mempunyai biaya operasional dan pemeliharaan yang relatif murah untuk mengolah air limbah laundry (Hermawati dkk., 2005; Hardyanti dan Rahayu, 2007; Stefhany dkk., 2013; Padmaningrum dkk., 2014; Putri dkk., 2016). Constructed wetland adalah sistem pengolahan terkontrol yang telah didesain dan dibangun dengan memanfaatkan proses alamiah yang melibatkan tumbuhan, tanah, dan mikroorganisme yang saling berinteraksi untuk pengolahan air limbah (Zhang, 2012; Hall, 2013). Pada prinsipnya sistem ini memanfaatkan hubungan simbiosis antara aktifitas mikroorganisme yang menempel pada akar tumbuhan air dalam menguraikan zat pencemar, dimana akar tumbuhan menghasilkan oksigen sehingga tercipta kondisi aerobik yang mendukung penguraian tersebut. Pada akhirnya di dalam constructed wetland tersebut terjadi siklus biogeokisme dan rantai makanan, sehingga sistem ini merupakan sistem berkelanjutan (Meutia, 2001).

Penggunaan sistem subsurface (SSF) constructed wetland dapat digunakan karena pada sistem ini air tidak menggenang di atas media tanam, tetapi mengalir di bawah media sehingga memiliki berbagai keuntungan. Salah satu keuntungannya adalah tumbuhan yang dapat beradaptasi lebih bervariasi, sehingga dapat digunakan sebagai taman dengan estetika yang baik (Suswati dan Wibisono, 2013).
Berbagai jenis tumbuhan dapat tumbuh dalam sistem SSF constructed wetland. Penelitian terdahulu melaporkan bahwa tumbuhan kayu apu (Pistia stratiotes L.), melati air (Echinodorus palaefolius), genjer (Limnocharis flava L.), eceng gondok (Eichhornia crassipes), kana (Thypa angustifolia), rumput payung (Cyperus Alternifolius), teratai (Nyphaea firecrest) dapat dimanfaatkan untuk pengolahan air limbah (Hermawati dkk., 2005; Hardyanti dan Rahayu, 2007; Sutrisno, 2009; Stefhany dkk., 2013, Padmaningrum dkk., 2014; Putri dkk., 2016; Setiyanto, dkk., 2016; Hariyanti, 2016).

Tumbuhan melati air (Echinodorus palaefolius) dan kayu apu (Pistia stratiotes L.) dapat digunakan sebagai alternatif tumbuhan akuatik untuk ditanam pada SSF constructed wetland untuk pengolahan air limbah laundry. Tumbuhan ini relatif dapat beradaptasi terhadap kelembaban media tanam yang cukup tinggi. Selain itu, kedua tumbuhan tersebut juga relatif mudah ditemukan dan dikembangbiakkan. Tumbuhan ini termasuk tumbuhan hias yang memiliki nilai estetika yang baik. Baik tumbuhan melati air (Echinodorus palaefolius) maupun kayu apu (Pistia stratiotes L.) merupakan jenis tumbuhan yang rentan terhadap adanya pencemar. Penelitian yang dilakukan oleh Padmaningrum dkk. (2014) menyimpulkan bahwa tumbuhan melati air (Echinodorus palaefolius) mampu menurunkan kandungan fosfat pada air limbah laundry sebesar 77,73\%, sedangkan tumbuhan kayu apu (Pistia stratiotes L.) mampu menurunkan kandungan fosfat pada air limbah laundry sebesar 41,90\% (Hermawati dkk., 2005). Penelitian ini bertujuan: 1) Mengkaji kadar $\mathrm{NH}_{3}$ dan $\mathrm{PO}_{4}$ pada limbah laundry dengan SSF constructed wetland, 2) Mengkaji kemampuan tumbuhan melati air (Echinodorus palaefolius) dan kayu apu (Pistia stratiotes L.) dalam penurunan kadar $\mathrm{NH}_{3}$ dan $\mathrm{PO}_{4}$.

\section{METODE}

Penelitian dilakukan dalam skala laboratorium dengan sistem kontinyu. Variasi jenis tumbuhan yang digunakan dalam penelitian ini adalah melati air (Echinodorus palaefolius) dan kayu apu (Pistia stratiotes L.). Air limbah laundry diambil dari salah satu usaha industri laundry skala rumah tangga Bee Clean Laundry yang beralamat di Perumahan Griyo Mapan Sentosa Blok BH 20, Sidoarjo. Parameter utama yang diukur adalah penurunan kadar $\mathrm{NH}_{3}$ dan 
$\mathrm{PO}_{4}$. Tahapan penelitian akan dijelaskan sebagai berikut:

\section{a. Persiapan Alat dan Bahan}

Perencanaan debit air limbah laundry yang akan masuk ke dalam reaktor $1,7 \mathrm{~L} /$ menit dengan aliran kontinyu. Desain reaktor memiliki ukuran p x $1 \times$ t adalah $(73 \times 20 \times 35) \mathrm{cm}$. SSF constructed wetland menggunakan aliran horizontal atau beraliran bawah permukaan pada tumbuhan Echinodorus palaefolius dan Pistia stratiotes L. dengan media berpori yaitu pasir dan zeolit berdiameter 6-10 $\mathrm{mm}$. Tumbuhan yang akan digunakan pada penelitian memiliki kondisi awal dengan umur dan tinggi yang sama.

b. Aklimatisasi

Aklimatisasi bertujuan agar tumbuhan Echinodorus palaefolius dan Pistia stratiotes L. dapat beradaptasi dengan media tanam yang nantinya akan menjadi media tumbuh selanjutnya. Proses aklimatisasi ini dilakukan selama 7 hari dengan media pasir dan zeolit tanpa pencemar dan menggunakan air PDAM. Pemilihan tumbuhan Echinodorus palaefolius dan Pistia stratiotes L. yang digunakan untuk penelitian utama mempunyai karakteristik tumbuh subur dan tidak mengalami kematian. c. Pelaksanaan Penelitian

Penelitian dilakukan dengan mengalirkan air limbah laundry pada setiap reaktor SSF constructed wetland yang berisi media pasir dan zeolit. Penelitian utama dilakukan selama 7 hari, dengan pengambilan sampel dilakukan secara duplo. Parameter yang diukur adalah nilai suhu, $\mathrm{pH}$, kadar $\mathrm{NH}_{3}$, dan $\mathrm{PO}_{4}$. Metode analisis untuk menguji nilai suhu adalah dengan termometer, $\mathrm{pH}$ dengan menggunakan $\mathrm{pH}$ meter. Kadar $\mathrm{NH}_{3}$, dan $\mathrm{PO}_{4}$ diuji dengan metode spektrofotometri (Eaton dkk., 2005).

\section{HASIL DAN PEMBAHASAN}

\section{Karakteristik Air Limbah Laundry}

Hasil karakteristik awal air limbah laundry disajikan pada Tabel 1. Berdasarkan hasil analisis tersebut dapat diketahui bahwa nilai kadar $\mathrm{NH}_{3}$ dan $\mathrm{PO}_{4}$ air limbah laundry berturutturut adalah $14,4 \mathrm{mg} / \mathrm{L}$ dan $12,88 \mathrm{mg} / \mathrm{L}$. Kadar $\mathrm{NH}_{3}$ dan $\mathrm{PO}_{4}$ ini melebihi baku mutu berdasarkan Peraturan Gubernur Jawa Timur Nomor 72 Tahun 2013/.

Tabel 1. Hasil Karakterisasi Air Limbah Laundry

\begin{tabular}{clccc}
\hline No & Parameter & Satuan & Baku Mutu* & Hasil Uji \\
\hline 1. & Nilai $\mathrm{suhu}$ & $\left({ }^{0} \mathrm{C}\right)$ & - & 30 \\
2. & Nilai $\mathrm{pH}$ & - & $6-9$ & 7 \\
3. & Kadar $\mathrm{NH}_{3}$ & $\mathrm{mg} / \mathrm{L}$ & - & 14,4 \\
4. & Kadar $\mathrm{PO}_{4}$ & $\mathrm{mg} / \mathrm{L}$ & 10 & 12,88 \\
\hline
\end{tabular}

*Peraturan Gubernur Jawa Timur No. 72 Tahun 2013

\section{Nilai Suhu dan pH}

Nilai suhu pada semua reaktor selama penelitian berada dalam kisaran suhu optimum pertumbuhan mikroorganisme. Nilai suhu baik pada reaktor dengan tumbuhan melati air (Echinodorus palaefolius) maupun kayu apu (Pistia stratiotes L.) berlangsung berada dalam kisaran suhu mesofilik dengan nilai 27,00$36,00^{\circ} \mathrm{C}$. Nilai ini sejalan dengan hasil penelitian yang dilakukan oleh Ratnawati dkk. (2011) yang menyatakan bahwa kondisi suhu mesofilik merupakan suhu yang sesuai untuk proses biodegradasi.

Nilai pH pada semua reaktor selama penelitian berlangsung termasuk dalam kondisi netral untuk semua reaktor selama penelitian berlangsung dengan kisaran nilai adalah 6-8. Ratnawati dkk. (2016) menyimpulkan bahwa nilai $\mathrm{pH}$ netral dengan nilai 6-8 merupakan nilai yang optimum untuk pertumbuhan mikroorganisme.

\section{Penurunan Kadar $\mathrm{NH}_{3}$}

Hasil analisis kadar $\mathrm{NH}_{3}$ dengan constructed wetland baik menggunakan tumbuhan Echinodorus palaefolius dan Pistia stratiotes L. disajikan pada Gambar 1 dan Gambar 2. Dapat diamati pada Gambar 1. bahwa baik pada reaktor dengan tumbuhan melati air (Echinodorus palaefolius) maupun kayu apu (Pistia stratiotes L.) mengalami penurunan kadar $\mathrm{NH}_{3}$ dari awal sampai dengan akhir penelitian. Kadar $\mathrm{NH}_{3}$ awal adalah 14,4 $\mathrm{mg} / \mathrm{L}$. Kadar $\mathrm{NH}_{3}$ akhir pada reaktor dengan tumbuhan melati air (Echinodorus palaefolius) maupun kayu apu (Pistia stratiotes L.) berturutturut adalah $3,18 \mathrm{mg} / \mathrm{L}$ dan $4,39 \%$.

Efisiensi penurunan kadar $\mathrm{NH}_{3}$ pada reaktor tumbuhan melati air (Echinodorus palaefolius) mencapai $82 \%$, sedangkan pada 
reaktor tumbuhan kayu apu (Pistia stratiotes L.) adalah 70\% (Gambar 2). Pada proses secara biologis kadar $\mathrm{NH}_{3}$ awal tersedia dalam jumlah yang besar dan akan berangsur-angsur menurun sampai menjadi senyawa nitrat yang lebih stabil (Al Kholif dan Ratnawati, 2016). Penurunan kadar $\mathrm{NH}_{3}$ pada air limbah laundry ini disebabkan karena adanya volatilisasi kadar

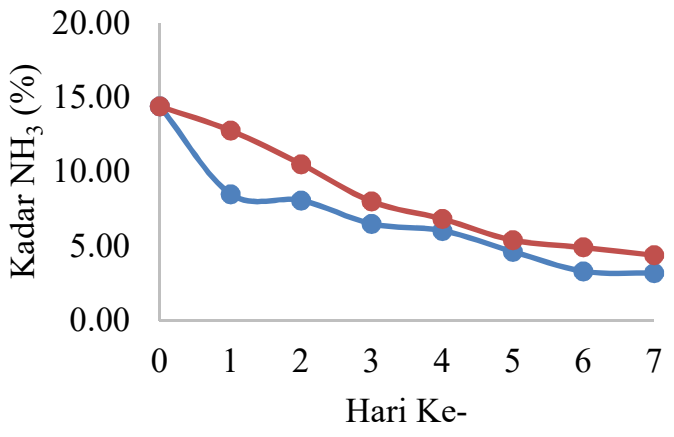

$$
\multimap \text { Melati Air } \longrightarrow \text { Kayu Apu }
$$

Gambar 1. Penurunan Kadar $\mathrm{NH}_{3}$

Tumbuhan dan/ atau kombinasinya dengan mikroorganisme yang ada pada air limbah laundry akan melakukan imobilisasi dan pengambilan kadar $\mathrm{NH}_{3}$. SSF constructed wetland memanfaatkan hubungan sinergis yang terjadi secara alami antara tumbuhan, mikroorganisme, dan lingkungan. Akar tumbuhan melati air (Echinodorus palaefolius) dan kayu apu (Pistia stratiotes L.) melakukan imobilisasi polutan dengan cara mengakumulasikan, mengadsorpsi pada permukaan akar dan mengendapkan presipitat polutan dalam zone akar. Akar tumbuhan selanjutnya akan mengadsorpsi larutan polutan

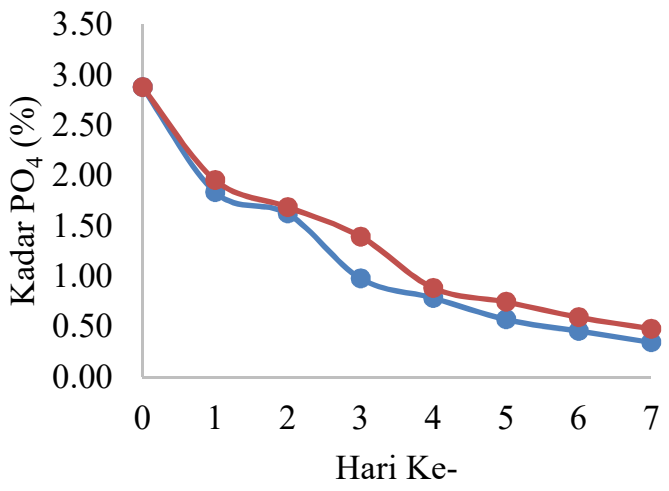

$\longrightarrow$ Melati Air $\longrightarrow$-Kayu Apu

Gambar 3. Penurunan Kadar $\mathrm{PO}_{4}$
$\mathrm{NH}_{3}$, ammonifikasi, imobilisasi sebagai senyawa nitrogen oleh mikroorganisme dan akar tumbuhan, serta konversi menjadi nitrat. Bakteri Nitrosomonas melakukan proses nitrifikasi dengan mengoksidasi amonium menjadi nitrit dan Nitrobacter akan mengubahnya menjadi nitrat (Rini dkk., 2015).

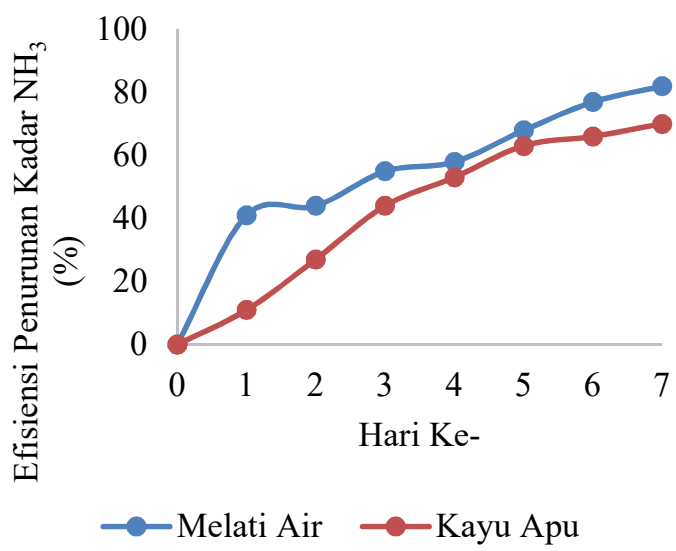

Gambar 2. Efisiensi Penurunan Kadar $\mathrm{NH}_{3}$ sekitar akar ke dalam akar dan menranslokasi ke dalam organ tumbuhan seperti daun atau batang.

\section{Penurunan Kadar $\mathrm{PO}_{4}$}

Hasil analisis kadar $\mathrm{PO}_{4}$ dengan constructed wetland baik menggunakan tumbuhan melati air (Echinodorus palaefolius) dan kayu apu (Pistia stratiotes L.) disajikan pada Gambar 3 dan Gambar 4. Kadar $\mathrm{PO}_{4}$ mengalami penurunan dari awal sampai dengan akhir penelitian (Gambar 3). Kadar $\mathrm{PO}_{4}$ akhir pada reaktor menggunakan tumbuhan melati air (Echinodorus palaefolius) dan kayu apu (Pistia stratiotes L.) berturut-turut adalah $0,35 \mathrm{mg} / \mathrm{L}$ dan $0,48 \mathrm{mg} / \mathrm{L}$.

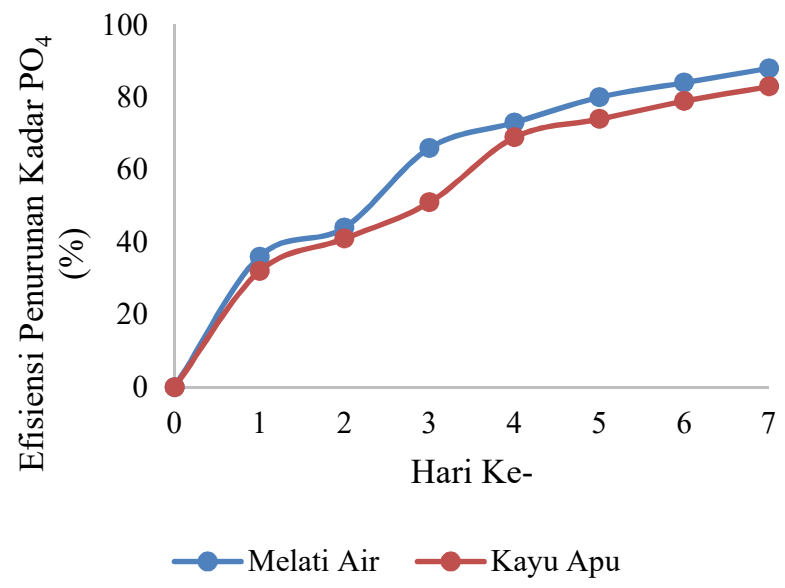

Gambar 4. Efisiensi Penurunan Kadar $\mathrm{PO}_{4}$ 

Laundry

\begin{abstract}
Efisiensi penurunan kadar $\mathrm{PO}_{4}$ pada reaktor dengan tumbuhan melati air (Echinodorus palaefolius) dan kayu apu (Pistia stratiotes L.) masing-masing adalah $88 \%$ dan 83\%. Dalam air limbah, kadar $\mathrm{PO}_{4}$ umumnya dalam bentuk terlarut tersuspensi atau terikat di dalam sel organisme. Kadar $\mathrm{PO}_{4}$ organik dapat terjadi dari ortofosfat yang terlarut melalui biologis karena baik bakteri maupun tumbuhan menyerap kadar $\mathrm{PO}_{4}$ dari untuk keperluan

Penurunan kadar fosfat selama proses pengolahan juga dapat disebabkan oleh adanya aktivitas mikroorganisme rhizosfer pada akar tumbuhan melati air (Echinodorus palaefolius) dan kayu apu (Pistia stratiotes L.) yang merombak senyawa ortofosfat yang merupakan builder pada deterjen menghasilkan senyawa fosfat sederhana yang selanjutnya akan diserap oleh akar tumbuhan sebagai nutrisi bagi tumbuhan melakukan fotosintesis.
\end{abstract} pertumbuhannya. Dalam reaktor sistem SSF constructed wetland ini melati air (Echinodorus palaefolius) dan kayu apu (Pistia stratiotes L.), kadar $\mathrm{PO}_{4}$ sudah terurai menjadi molekul yang lebih sederhana yaitu ortofosfat. Sehingga dapat digunakan oleh tumbuhan melati air (Echinodorus palaefolius) dan kayu apu (Pistia stratiotes L.) dan mikroorganisme untuk pertumbuhan sendiri. Artiyani (2011) menyimpulkan bahwa kadar $\mathrm{PO}_{4}$ merupakan salah satu nutrien penting bagi pertumbuhan tanaman dan selain itu pada fase awal nutrien sangat dibutuhkan untuk pertumbuhan mikroorganisme pada akar tumbuhan sehingga penurunan kadar kadar $\mathrm{PO}_{4}$ dalam sampel air deterjen pada 10 hari awal sangat nyata

\section{KESIMPULAN}

Berdasarkan hasil penelitian dapat disimpulkan bahwa nilai efisiensi penurunan kadar $\mathrm{NH}_{3}$ air limbah laundry menggunakan SSF constructed wetland adalah sebesar 70$82 \%$, sedangkan penurunan kadar $\mathrm{PO}_{4}$ mencapai $83-88 \%$. Jenis tumbuhan yang paling efektif dalam menurunkan kadar $\mathrm{NH}_{3}$ dan $\mathrm{PO}_{4}$ dengan menggunakan SSF constructed wetland adalah tumbuhan melati air (Echinodorus palaefolius).

\section{UCAPAN TERIMA KASIH}

Ucapan terima kasih ditujukan kepada laboratorium Teknik Lingkungan Universitas PGRI Adi Buana (UNIPA) Surabaya sebagai tempat penelitian dan analisis sampel.

\section{DAFTAR PUSTAKA}

Al Kholif, M. dan Ratnawati, R., (2016), "Removal Ammonia $\left(\mathrm{NH}_{3}\right)$ in Industrial Chicken Slaughterhouse by Anaerobic Biofilter", Prosiding Seminar Internasional the 1st Seminar on Environment and Health Toward SDG'S Achievement 2030 Integration System on Environment and Healt Sustainability, hal. 171-179, Surabaya.

Artiyani, A., (2011), "Penurunan Kadar N-Total dan P-Total pada Limbah Cair Tahu dengan Metode Fitoremediasi Aliran Batch dan Kontinyu Menggunakan Tanaman Hydrilla verticillata, Jurnal Spectra, Fakultas Teknik Sipil dan Perencanaan Institut Teknologi Nasional, Malang

Eaton, Andrew, D., Clesceri, Lenore, S., dan Greenberg, Arnold, E., (2005), :Standard Methods for the Examination of Water and Wastewater, 21th edition, American Public Health Association, Washington.

Hall, GB., (2013), "Subsurface Wastewater Treatment Wetlands: Understanding the Barriers to Implementation in the Landscape", Master of Landscape Architecture, The University of Texas at Arlington.

Hardyanti, N., dan Rahayu, S.S., (2007), "Fitoremediasi Phospat dengan Pemanfaatan Tumbuhan Eceng Gondok (Eichhornia crassipes) (Studi Kasus pada Limbah Cair Industri Kecil Laundry)

Hariyanti, F., (2016), "Efektifitas Subsurface Flow-Wetland dengan Tanaman Eceng Gondok dan Kayu Apu delama Menurunkan Kadar COD dan TSS pada Limbah Pabrik Saus, Skripsi Fakultas Kesehatan Masyarakat, Universitas Muhammadiyah Semarang.

Hermawati, E., Wiryanto, dan Solichatun, (2005), "Fitoremediasi Limbah Detergen Menggunakan Kayu Apu (Pistia stratiotes L.) dan Genjer (Limnocharis flava L.), Biosmart Vol. 7 (2): 115-124.

Padmaningrum, RT., Aminatun, T., Yuliati, (2014), "Pengaruh Biomasa Melati Air (Echinodorus palaefolius) dan Teratai (Nyphaea firecrest) terhadap Kadar Fosfat, BOD, COD, TSS, dan Derajat Keasaman Limbah Cair Laundry", Jurnal Penelitian Saintek, Vol. 19 (2): 64-74.

Peraturan Gubernur Jawa Timur Nomor 72 Tahun 2013 tentang Baku Mutu Air Limbah Bagi Industri dan/ atau Kegiatan Usaha Lainnya 
Putri, MH., Jazuli, N., dan Dangiran, HL., (2016), "Perbedaan Efektivitas Constructed Wetland Sub Surface Flow System dan Free Water Surface pada Tanaman Cattail untuk Menurunkan BOD, COD, dan Fosfat Limbah Laundry di Kelurahan Tembalang, Kota Semarang, Jurnal Kesehatan Masyarakat Vol. 4 (5): 18-26.

Ratnawati, R., Slamet, A., dan Hermana J., (2011), "Efek Penambahan Unsur Kalium dan Aerasi terhadap Kinerja Alga-Bakteri untuk Mereduksi Polutan pada Air Boezem Morokrembangan, Surabaya", Prosiding Seminar Nasional VIII Teknik Lingkungan ITS dan Seminar Nasional VII Ikatan Alumni Teknik Penyehatan Indonesia (IATPI), Surabaya.

Ratnawati, R., Trihadiningrum, Y., dan Juliastuti, SR., (2016), "Composting of Rumen Content Waste Using Anaerobic-Anoxic-Oxic $\left(\mathrm{A}^{2} \mathrm{O}\right)$ Methods", Journal of Solid Waste Technology and Management. Vol. 42 (2): 98-106.

Rini, IDWS., Ratnawati, R., dan Trihadiningrum, Y., (2015), "Pola Perubahan Kadar N-anorganik pada Proses Pengomposan Limbah Padat Rumah Potong Hewan dengan Sistem Aerobik", Prosiding Seminar Nasional Manajemen Teknologi XXII, hal. A-49-1 s/d A-49-8.

Setiyanto, RA., Darundiati, YH., dan Joko, T., (2016), "Efektivitas Sistem Constructed Wetlands Kombinasi Melati Air (Echinodorus palaefolius) dan Karbon Aktif dalam Menurunkan kadar COD (Chemical Oxygen Demand) Limbah Cair Rumah Sakit Banyumanik Semarang, Jurnal Kesehatan Masyarakat, Vol. 4 (1): 436-441.

Stefhany, CA., Sutisna, M., Pharmawati, K., (2013), "Fitoremediasi Phospat dengan menggunakan Tumbuhan Eceng Gondok (Eichhornia crassipes) pada Limbah Cair Industri Kecil Pencucian Pakaian (Laundry)", Reka Lingkungan - Jurnal Institut Teknologi Nasional, Vol. 1 (1): 1-11.

Suswati, ACSP., dan Wibisono, G., (2013), "Pengolahan Limbah Domestik dengan Teknologi Taman Tanaman Air (Constructed Wetlands)", Indonesian Green Technology Journal, Vol. 2 (2): 70-77.

Sutrisno, J., (2009), "Pemanfaatan Rumput Payung (Cyperus alternifolius) dan Melati Air (Echinodorus palaefolius) dalam Sistem Subsurface Wetland pada Media Pasir untuk Penurunan Kandungan $\mathrm{BOD}_{5}$ Air Limbah Domestik. Universitas PGRI Adi Buana, Surabaya.

Meutia, A. A., (2001), "Lahan Basah Buatan Untuk Membersihkan Air Sungai Citarum (Sebuah Gagasan)", Prosiding Lokakarya "Selamatkan Citarum” Serpong, 10-11 April 2001. Wetland International- Indonesian Programme. pp. 155-156.

Zhang, Y., (2012), "Design of a Constructed Wetland for Wastewater Treatment and Reuse in Mount Pleasant, Utah", Master of Landscape Architecture, Utah University. 